\title{
Atención visual a las señales de consumo de tabaco: un estudio preliminar empleando el seguimiento ocular
}

\author{
Mario Arturo Téllez Rojas (DI', Nicolás Javier Vila Carranza', Fátima Alejandra Rojas Iturria', Roberto Jiménez Castillo' \\ I Facultad de Estudios Superiores Iztacala, Universidad Nacional Autónoma de México. Grupo de Investigación Aprendizaje Asociativo Humano. \\ Estado de México, México.
}

\section{RESUMEN}

Introducción: la atención es un proceso básico relacionado con el comportamiento adictivo. En fumadores, los estímulos asociados al consumo son relevantes debido a que están presentes en el inicio y en la consolidación del hábito tabáquico. Por ello, para contribuir en la comprensión de las conductas adictivas con medidas objetivas, se presenta un estudio sobre atención a través de técnicas de seguimiento ocular que apoya el proceso clínico de las personas que buscan dejar de fumar. Objetivo: estudiar el sesgo atencional con imágenes relacionadas con el consumo de tabaco en participantes fumadores y no fumadores, mediante la técnica de seguimiento ocular. Método: participaron ocho estudiantes universitarios, los cuales fueron asignados a dos grupos en función de su puntaje en la prueba de Fagerström. La tarea experimental consistió en la presentación aleatoria de 15 imágenes relacionadas al consumo de tabaco y 15 imágenes neutrales. Durante el experimento se registraron las fijaciones visuales, latencia y tiempo en cada imagen, mediante un rastreador ocular. Resultados: un análisis estadístico mostró diferencias significativas entre fumadores moderados y no fumadores cuando se presentaron imágenes relacionadas con el consumo de tabaco en las tres medidas. Asimismo, un análisis cualitativo de los resultados muestra diferencias entre los participantes cuando se les presentaron imágenes neutras e imágenes relacionadas con tabaco. Discusión y conclusiones: se sugiere que los participantes fumadores presentan un sesgo atencional hacia las imágenes relacionadas con el consumo de tabaco.

Palabras clave: consumo de tabaco, sesgo atencional, estudiantes universitarios, mediciones de movimiento ocular.

\begin{abstract}
Introduction: attention is a basic process related to addictive behavior. In smokers, the stimuli associated with consumption are relevant because they are present at the beginning and in the consolidation of the smoking habit. Therefore, to contribute to the understanding of addictive behaviors with objective measures, a study through eye-tracking techniques is presented. This would support the clinical process of people seeking to quit smoking. Objective: to study the attentional bias with images related to tobacco consumption in smoking and non-smoking participants, using an eye-tracking technique. Method: eight university students participated, who were assigned to two groups based on their Fagerström Test score. The experimental task consisted of the random presentation of 15 images related to tobacco consumption and 15 neutral images. During the experiment, visual fixations, latency and time to each image were recorded using an eye tracker. Results: a statistical analysis showed significant differences between moderate smokers and non-smokers when images related to tobacco use were presented in the three measure. Likewise, a qualitative analysis of the results shows differences between the participants when they were presented with neutral images and images related to tobacco. Discussion and conclusions: it is suggested that in the smoking participants there is an attentional bias towards the images related to tobacco consumption.
\end{abstract}

Keywords: tobacco consumption, attentional bias, university students, eye movement measurements.

\footnotetext{
Autor de correspondencia: Teléfono: 5532486637

Correo electrónico: ma.tellezrojas@gmail.com

Recibido: 06 de julio de 2020

Aceptado: 17 de febrero de 2021

doi: 10.28931/riiad.2021.1.03
}

Mario Arturo Téllez Rojas. Facultad de Estudios Superiores Iztacala, UNAM. Grupo de Investigación Aprendizaje Asociativo Humano. 


\section{INTRODUCCIÓN}

En los últimos años el consumo de sustancias adictivas a nivel global ha aumentado $30 \%$ con respecto a 2009 , así como sus consecuencias negativas (Oficina de las Naciones Unidas contra la Droga y el Delito [UNODC], 2019). El tabaquismo es responsable de la muerte de más de nueve millones de personas al año, entre fumadores activos y personas expuestas al humo de tabaco (Organización Mundial de la Salud [OMS], 2019). En el año 2017, en México, se calcula que hubo aproximadamente 49,189 muertes por año, es decir, $8 \%$ del total de muertes en el país se atribuyen a causas derivadas del consumo de tabaco (Encuesta Global de Tabaquismo en adultos [GATS], 2015; Instituto de Efectividad Clínica y Sanitaria, 2017; Levy et al., 2017). Adicionalmente, se ha observado que la edad de inicio de consumo ha disminuido, lo que enfatiza la necesidad de comprender el comportamiento del consumo de tabaco, a fin de mejorar el desarrollo de programas de atención, tratamiento y prevención (Encuesta Nacional de Consumo de Drogas, Alcohol y Tabaco [ENCODAT], 2017).

Dentro de este contexto, es de utilidad estudiar los mecanismos básicos que subyacen al consumo de tabaco debido a que están directamente relacionados con el comportamiento de consumo y de búsqueda de la droga (Hogarth \& Duka, 2006; Robinson \& Berridge, 2008). Al respecto, Vila (2016) señala que en el estudio de la conducta adictiva se deben considerar los mecanismos básicos de aprendizaje, memoria y atención, dada su trascendencia para el desarrollo, mantenimiento y tratamiento de las adicciones.

De La Torre (2002) ha sugerido que la atención no es un constructo unitario. En este sentido, se pueden mencionar las teorías pioneras que tuvieron como enfoque central el procesamiento de la información, como el modelo de Donald E. Broadbent en la década de los 50 (Munar et al., 1999), hasta modelos más complejos como el de Petersen y Posner (2012) que integran a la psicología con las neurociencias para describir los mecanismos de la atención (Fernández, 2014). Dicho modelo se basa en el concepto de redes cognitivas y anatómicas de la atención (alerta, orientación, ejecutivo), considerándolas independientes y específicas en su funcionamiento, pero que interactúan entre sí; por lo tanto, las redes atencionales son supramodales, es decir, estas redes desempeñan diferentes tareas de forma independiente de la modalidad de estímulos (Fernández, 2014). Por otro lado, el enfoque conductual ha tenido contribuciones importantes al estudio de la atención (Vila et al., 2017).

En la última década, propuestas teóricas sugieren que los sesgos en la atención selectiva juegan un papel fundamental en el desarrollo y mantenimiento de la adicción a las drogas; en particular, la teoría de la sensibilización del incentivo de Robinson y Berridge es el modelo que más apoyo empírico ha recibido en los últimos años (Ventura et al., 2011). De acuerdo con este modelo, un consumo abusivo y persistente de una sustancia potencialmente adictiva produce un sesgo en el procesamiento hacia estímulos asociados al consumo de drogas; es decir, la exposición repetida al uso de sustancias en individuos susceptibles puede cambiar las células cerebrales y los circuitos que normalmente regulan la atribución de incentivos y la relevancia de los estímulos; por lo que tales circuitos aumentan su sensibilidad de tal manera que se obtienen niveles patológicos, lo que produce un incremento en la atención a señales previas al consumo (Berridge \& Robinson, 2011; Robinson \& Berridge, 2008). Con el consumo repetido, la búsqueda y el uso de drogas se convierten en un hábito automático (Hogarth et al., 2003; Robinson \& Berridge, 2008; Ventura et al., 2011).

En concordancia con lo anterior, Skinner (1953) ofrece una definición operacional de la atención y señala que un organismo atiende un aspecto particular de un estímulo, si algún cambio físico en el mismo produce cambios sistemáticos en su conducta. Es decir, un fumador atiende y selecciona estímulos particulares que se han asociado a su conducta de consumo, cuando ante su presencia se inicia la búsqueda por el tabaco. De este modo, desde un punto de vista conductual (Vila et al., 2017) la atención está asociada a información aprendida y un organismo debe ser capaz de descartar información irrelevante o redundante, por lo que responder o no a las características del estímulo relevante puede afectar y controlar su comportamiento (Mackintosh, 1975).

La técnica de seguimiento ocular (en inglés eye tracking) ofrece una oportunidad para el estudio de los procesos atencionales desde un punto de vista conductual, la cual es coherente con la definición de atención considerada en el presente estudio, debido a que registra hacia dónde se despliega la atención visual (Field et al., 2011). Además, la técnica permite conocer la posición de los ojos y los movimientos sacádicos ante determinado estímulo visual, lo que facilita la observación y el registro de la conducta estudiada. Es un método no invasivo para registrar el movimiento ocular, por lo que los datos se registran en situaciones controladas y sin interferencias medioambientales (ruidos, olores) o de otros estímulos visuales (Wu et al., 2018). En años recientes, algunos autores han sugerido que las fijaciones oculares pueden ser consideradas medidas conductuales de la atención (Duchowski, 2017; Pérez et al., 2019).

En concordancia con lo anterior, en el presente estudio se consideran como medidas conductuales de atención: 1) la latencia en atender un estímulo, lo cual implica 
el tiempo que tarda en atenderse dentro de un área de interés (imagen neutra o imagen de tabaco) ; 2) el número de veces que un área de interés es observada, es decir, la frecuencia con la que se observa el estímulo (imagen neutra o imagen de tabaco); y 3) el porcentaje de tiempo que se observa dicha área respecto al tiempo total de duración del estímulo. Cabe señalar que el considerar tres medidas conductuales de atención que varíen conjuntamente cuando se mira una imagen permite una mayor validez interna del estudio (Hernández et al., 2014), al tener un índice más preciso de la atención visual a un estímulo, aspecto que no está presente en otros estudios sobre sesgo atencional y uso de la técnica de rastreo ocular (Duchowski, 2017; Field et al., 2011; Pérez et al., 2019; Ventura et al., 2011).

En el ámbito de la salud, la técnica de seguimiento ocular ha sido un gran aporte para estudiar el papel de la atención en el consumo de distintas sustancias. Field et al., (2011) señalan que las personas que abusan del alcohol, el tabaco o drogas ilícitas tienen un sesgo atencional para las señales relacionadas con su consumo. En lo que respecta al tabaco, se ha encontrado un sesgo atencional mayor en fumadores "severos" vs fumadores "leves", sugiriendo además que la restricción de la sustancia puede influir en el sesgo atencional. Otro estudio observó que las señales relacionadas con la nicotina provocan una expectativa de su consumo, junto con un apetito emocional que refleja su valor biológico, así como su función reforzante (Hogarth \& Duka, 2006). Además, existe evidencia de que la atención es diferente entre consumidores y no consumidores, por ejemplo, cuando se presentan imágenes asociadas al consumo de tabaco vs imágenes neutras (Crespo et al., 2007), en imágenes de cajetillas de cigarros (Shankleman, et al., 2015); incluso imágenes relacionadas con el consumo de tabaco fueron calificadas como agradables por fumadores (Orain-Pelissolo et al., 2004). En síntesis, los estudios descritos con anterioridad sugieren que las personas con consumo de tabaco o con adicción a sustancias, legales o ilegales, muestran un sesgo atencional a señales relacionadas con dicha sustancia (Hogarth, et al., 2008) lo cual es congruente con la teoría de sensibilización al incentivo (Berridge \& Robinson, 2011).

Debido a la importancia que tiene la atención en el inicio y consolidación del hábito tabáquico y a la escasez de estudios empíricos en México sobre los sesgos en la atención visual de fumadores (Morales et al., 2013), se considera necesario su estudio. En este sentido, se propone que los estudios sobre la atención incluyan más de una medida conductual, así como otras observaciones que aporten mayor validez metodológica. Además, se considera idóneo utilizar la teoría de sensibilización al incentivo de Robinson y Berridge (2008) para el estudio de los sesgos atencio- nales, ya que esta propuesta teórica es coherente con la perspectiva conductual y con los hallazgos relacionados con conductas de consumo de drogas y su adicción. Por ello, el objetivo de la presente investigación fue realizar un estudio preliminar, a fin de detectar en jóvenes estudiantes universitarios fumadores moderados, la presencia de un sesgo atencional a imágenes relacionadas con el consumo de tabaco, mediante la técnica de rastreo ocular y con el uso de tres medidas conductuales de atención, con lo que se espera que las medidas de latencia, número de fijaciones y el tiempo que se atiende a las imágenes de consumo varíen conjuntamente, evidenciando el sesgo atencional en participantes fumadores jóvenes, de igual forma que la evidencia adicional de un análisis cualitativo de la atención basado en mapas de calor.

\section{MÉTODO}

\section{Participantes}

Para la obtención de los datos se aplicó un muestreo intencional por conveniencia conformado por ocho estudiantes pertenecientes a una institución pública de educación superior del Estado de México, de los cuales cinco fueron hombres y tres mujeres, con un rango de edad entre 19 y 22 años $(M=19.75)$. Ningún participante abandonó el experimento. Para la distribución de los grupos se aplicó una prueba de dependencia a la nicotina. De esta manera, con el puntaje obtenido en la prueba se asignó a los participantes al grupo de fumadores moderados (GFM) o al grupo de no fumadores (GNF); cada grupo estuvo constituido por cuatro participantes.

\section{Instrumento}

Cuestionario de Fagerström para la Dependencia a la Nicotina (CFDN). Mide la dependencia a la nicotina con seis reactivos que consideran los siguientes indicadores: la frecuencia de consumo, periodicidad y cantidad de sustancia utilizada en las primeras horas después de despertarse, el primer cigarro de la mañana, el control de consumo e intentos de dejar de fumar. Los puntajes de la prueba determinan el nivel de dependencia, que va de leve (0-4), moderada (5-6) a alta (mayor de 7). Este instrumento fue validado y demostró una alta confiablidad, con coeficientes de correlación de 0.92 test-retest y 0.99 para la confiablidad interna. La evaluación de la consistencia interna dio un Alfa de Cronbach de 0.83 (Fagerström et al., 1996).

\section{Materiales}

Los participantes realizaron la tarea empleando una computadora de escritorio con pantalla táctil. Se utiliza- 
ron en total 30 diapositivas, de las cuales 15 están estandarizadas por el Sistema Internacional de Imágenes Afectivas (International Affective Picture System [IAPS]; Lang et al., 2005). Las imágenes utilizadas fueron: 1850, 2037, 2191, 2838, 2480, 2515, 2530, 4622, 4641, 5628, $5831,5836,7493,8030,8465$, en ese orden. Las IAPS son un conjunto de fotografías estandarizadas para el estudio experimental de la emoción y la atención. Estas imágenes fueron diseñadas para contar con un conjunto de diapositivas a color que ofrecen una amplia variedad de categorías semánticas. Tienen tres características: valencia, arousal y dominancia, para fines del estudio se consideraron únicamente las de valencia neutral y positiva (imágenes agradables). Las otras 15 diapositivas fueron de elaboración propia con estímulos asociados a la conducta de consumo de tabaco.

Para diseñar las imágenes de consumo de tabaco del presente estudio, se consideraron los criterios y aportaciones de análisis previos relacionados con el consumo de tabaco (Gantiva et al., 2012; Pérez et al., 2019) y se realizaron utilizando una cámara fotográfica de alta definición, de acuerdo con siete categorías: a) celebraciones sociales; b) tiempo libre; c) ambientes de estudio; d) café y cigarrillos; e) fumadores solos; f) cigarrillos y cajetillas; y g) ceniceros y cigarrillos.

En lo que respecta al registro de fijaciones visuales, se utilizó un rastreador ocular Eye-Tracker Gazepoint ${ }^{\circledR}$ modelo GP3 Desktop con una precisión de 0.5 a $1^{\circ}$ de ángulo visual, un rango de ajuste en la cámara de 60 $\mathrm{Hz}$ para el procesamiento de imágenes. Además, cuenta con cinco a nueve puntos de calibración, alcance de 25 $\mathrm{cm}$. de movimiento horizontal por $11 \mathrm{~cm}$. de movimiento vertical y rango de profundidad de $\pm 15 \mathrm{~cm}$. de profundidad. En específico, los datos fueron registrados con una distancia de 60 a $80 \mathrm{~cm}$. entre el rastreador ocular y los ojos de los participantes. Todas las calibraciones fueron de nueve puntos y se procedió a continuar con la tarea experimental sólo cuando la calibración era la óptima, es decir, 9 de 9 puntos correctamente calibrados. La calibración consiste en seguir con la mirada una señal (puntero) que da la interfaz del software Gazepoint, el cual coordina los movimientos sacádicos, el rastreador ocular y la pantalla. Para hacer el análisis de datos se utilizó el Software Gazepoint Analysis UX Edition. Se empleó también una silla de oficina con soporte en el cuello para garantizar que los participantes mantuviesen la cabeza inmóvil.

Finalmente, para definir el área de interés se seleccionó la figura de cada imagen para las relacionadas con el consumo de tabaco, por ejemplo, un cenicero, una taza de café o un cigarro encendido; en contraste, las imágenes neutras contenían una pareja, un paisaje, unos camellos u otros objetos.

\section{Procedimiento}

La tarea experimental consistió en la presentación aleatoria de 15 diapositivas de estímulos relacionados con el consumo de tabaco y 15 diapositivas neutras. Todas las imágenes tenían una figura y fondo definidos. La presentación de cada imagen fue de 5s, como intervalo entre estímulos (IEE) se empleó una pantalla negra con una cruz de fijación blanca al centro, con una duración de 2s. Para la medición de la atención se consideraron tres variables dependientes: a) la latencia en atender un estímulo dentro de un área de interés; b) el número de veces que dicha área de interés fue observada, y c) el porcentaje de tiempo durante el cual se observó el área de interés respecto al total de la duración del estímulo. El registro y análisis de las tres mediciones conductuales de atención visual se realizó a través de un rastreador ocular (eye tracker), que detectó los movimientos sacádicos durante la presentación de las imágenes.

\section{Consideraciones éticas}

A los participantes se les solicitó su colaboración de manera verbal y al final del experimento se les dio una explicación de los objetivos. La investigación cumplió con los requerimientos éticos solicitados por la Facultad de Estudios Superiores Iztacala acordes con el código ético del psicólogo (Sociedad Mexicana de Psicología, 2009). Todos los participantes firmaron un consentimiento informado en el que se les explicó que sus datos son confidenciales y anónimos, además de que podían abandonar en cualquier momento el experimento si así lo deseaban.

\section{Análisis de datos}

Para el análisis de la información se utilizaron métodos de estadística descriptiva (porcentajes y promedios) y pruebas estadísticas $t$ para dos muestras independientes, empleando el programa SPSS v20. Las pruebas $t$ compararon el comportamiento de los grupos en cada medida de atención. Para fines del presente estudio, se contemplaron como variables dependientes de la atención: 1) la latencia en atender un estímulo dentro de un área de interés; 2) el tiempo en segundos que dicha área de interés fue observada (fijaciones), y 3 ) el porcentaje que este tiempo representa respecto al total de la duración del estímulo. La información obtenida fue almacenada y procesada en Microsoft Excel® (Microsoft Corp.). Para cumplir con los criterios de normalidad de las pruebas $t$, se realizaron pruebas de normalidad Shapiro-WiIk, las cuales determinaron que los datos se distribuían normalmente (el estadístico W fue mayor que el nivel de 
significación dado, por lo que se acepta la hipótesis nula en la prueba de normalidad). Adicionalmente, se realizó un análisis descriptivo de los promedios de los puntajes obtenidos en las tres medidas de atención.

Finalmente, se integra un análisis cualitativo que explora las diferencias entre los participantes a través de mapas de calor empleando el Software Gazepoint Analysis UX Edition. El análisis consistió en observar cada uno de los mapas; posteriormente, se compararon de manera simultánea los mapas del Grupo de Fumadores Moderados y los mapas del Grupo de No Fumadores. No se realizó una medición de las proporciones de los colores en los mapas de calor, por lo que la apreciación fue subjetiva

\section{RESULTADOS}

En general, las medidas de atención a ambos tipos de imágenes (imágenes de tabaco e imágenes neutras), sugieren la presencia de un sesgo atencional que hace que los participantes que consumen tabaco (GFM) observen más rápido los estímulos relacionados con el consumo de tabaco (menor latencia para mirar imágenes de tabaco). Además, su mirada se ubica en estos estímulos un mayor número de veces (mayor número de fijaciones) y los participantes miran estos estímulos por más tiempo (mayor porcentaje del tiempo total dentro del área de interés).

Un análisis estadístico de las tres medidas para las imágenes de tabaco, muestra que la latencia entre ambos grupos presenta una diferencia significativa entre los participantes del GFM ( $M=0.547$ segundos con el GNF $(M=1.423 \mathrm{~s} ; t(6)=3.487, p=0.036)$. Adicionalmente, ambos grupos difieren significativamente en el porcentaje de tiempo total en mirar el área de interés $(t(6)=10.334$, $p=$ en 0.001) y en el número de fijaciones a la misma ( $t(6)$ $=12.464, p=0.001$ ), lo que sugiere que el GFM atiende más las imágenes de tabaco que el GNF.

En cuanto a las imágenes neutras, no se encontraron diferencias entre ambos grupos en la latencia al área de interés, para el GFM ( $M=0.635$ segundos) en comparación con el GNF ( $M=0.609 \mathrm{~s}) ;(t(6)=0.143, p>0.05)$, ni en el número de fijaciones, considerando para GFM $(M=$ 6.58) y para GNF $(M=6.76) ;(t(6)=-0.191, p>0.05)$. En cuanto al porcentaje de tiempo total de atención área de interés, tampoco existen diferencias significativas, para el GFM $(M=33.02 \%)$, en comparación con el GNF $(M=$ $36.48 \%) ;(t(6)=-0.567 . p>0.05)$. Los resultados de las medidas de atención en las imágenes neutras sugieren que tanto los fumadores moderados como los no fumadores atienden de forma similar estas imágenes.

El análisis cuantitativo de las pruebas $t$ realizadas, a cada una de las medidas de atención empleadas en el presente trabajo (latencia, número fijaciones y porcentaje de tiempo), permite sugerir que las tres medidas de atención difieren consistentemente entre los grupos y dan cuenta de una preferencia de los participantes del GFM para mirar frecuentemente los elementos de imágenes relacionados al consumo del tabaco por más tiempo, antes de mirar otros elementos presentes en la imagen. Así, la covariación de las tres variables dependientes muestra diferencias en la atención a las imágenes de consumo de tabaco, entendida como el cambio de las tres medidas conductuales, que es mayor para el GFM.

Un análisis descriptivo para las tres medidas de atención, señala para el caso de la latencia, que el GNF tarda más tiempo en atender el estímulo o Área de Interés (AI) que el GFM cuando se trata de dirigir su mirada a las imágenes de tabaco. La diferencia en los promedios de las puntaciones entre ambos grupos es de $0.952 \mathrm{~s}$, mientras que para las imágenes neutras la diferencia es de $0.036 \mathrm{~s}$. Para el número de fijaciones en las imágenes de tabaco existen diferencias entre ambos grupos. El grupo de GFM obtuvo en promedio 8.079 y el promedio del grupo GNF fue de 4.616, es decir, en lo que respecta a las imágenes neutras los promedios de ambos grupos fueron similares. Finalmente, al comparar los puntajes de los grupos se observa también una diferencia en el porcentaje de tiempo total que se atendieron los estímulos presentados. Para las imágenes de tabaco, el GFM en promedio $45.23 \%$ las atendió, en cuanto al GFM sólo $21.51 \%$ del tiempo. Para el caso de las imágenes neutras, la diferencia fue de aproximadamente $3 \%$ entre ambos grupos. En la figura 1 se muestran los promedios obtenidos por cada participante en las tres mediciones y se hace la comparación entre ambos grupos. Cabe señalar que se consideran las 30 imágenes utilizadas en el estudio, 15 imágenes de tabaco y 15 imágenes neutras.

Finalmente, en la Figura 2 un análisis cualitativo muestra las diferencias por medio de mapas de calor en un ejemplo representativo de las comparaciones realizadas entre una persona que fuma vs. una que no fuma; asimismo, se ilustra cómo se distribuye la atención con una imagen relacionada con el consumo de tabaco y con una imagen neutra. La figura muestra diferencias cualitativas con respecto a la atención entre los participantes del GFM y el GNF, mediante la apreciación subjetiva de las proporciones e intensidades de los mapas de calor en dos imágenes representativas. En estas imágenes, las zonas "calientes" o de mayor intensidad señalan dónde coinciden las zonas de referencia viso-espacial con mayor frecuencia, es decir, al rastrear la fijación y posición de la mirada del usuario se teñirá de rojo si es focalizada la atención en un punto determinado, pero si la intensidad es menor puede llegar 
Figura 1

Se muestran los promedios de los ocho participantes en las tres medidas de atención. La columna de la izquierda muestra la latencia de la primera mirada para ambos tipos de imagen: En la parte central se muestran los promedios de los porcentajes del tiempo de observación total de ambos tipos de imágenes. Finalmente, en la tercera columna se presentan el número de fijaciones al área de interés de los dos tipos de imagen
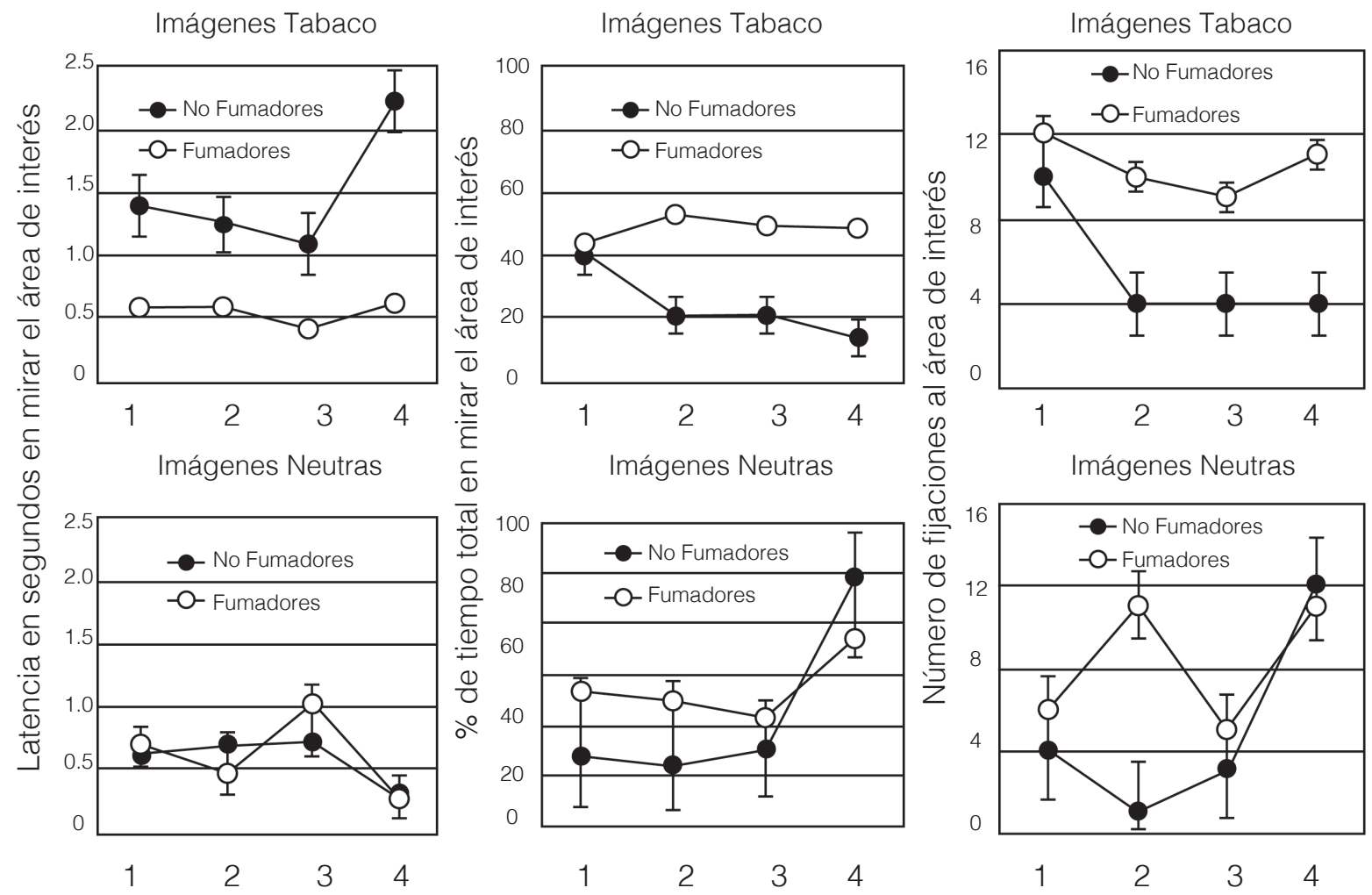

Participantes

a teñirse de color azul (zona fría). Considerando los mapas de calor presentados en la Figura 2, las zonas calientes (mayor intensidad) quedan representadas como semicírculos de color gris claro o emblanquecido, mientras que la zona fría queda ilustrada por un gris más oscuro (menor intensidad).

Los análisis realizados a partir de la distribución de zonas grises sugieren un sesgo atencional en el GFM para las imágenes de tabaco que no está presente en el GNF, pero no se observan diferencias en las zonas grises de ambos grupos para las imágenes neutras. La zona de interés estaba delimitada en ambos tipos de imágenes; sin embargo, los mapas de calor de las imágenes sugieren que la mirada de los participantes fumadores fue dirigida con mayor frecuencia hacia imágenes de tabaco, marcando así una intensidad mayor en el mapa de calor.

\section{DISCUSIÓN Y CONCLUSIONES}

El presente estudio confirma la existencia de un sesgo en la atención visual entre estudiantes universitarios fumadores y no fumadores que participaron en el estudio, ya que así lo muestran los análisis cualitativos y cuantitativos realizados. En primer lugar, se considera que las tres mediciones (latencia, número de fijaciones y porcentaje de tiempo) covarían sugiriendo diferencias entre la atención de los dos grupos. Así, los participantes del GFM atienden más rápido a las imágenes relacionadas con la conducta del consumo de tabaco (latencia corta), las miran más veces y por más tiempo, en consecuencia, sus mapas de calor se focalizan en el área de interés; aspectos que contrastan con los participantes del GNF, en quienes la atención fue más dispersa, su latencia fue mayor y miraron menos las imágenes relacio- 
Figura 2

Se muestra el mapa de calor en un ejemplo de las áreas de interés en las imágenes. En la primera columna (lateral izquierda) se presenta una imagen de tabaco y otra neutra, ambas con su zona de interés delimitada. El mapa de calor de no fumadores ilustra cómo el participante no atiende la imagen de tabaco. En la imagen 3, segunda columna, un participante no fumador miró el centro de la computadora y la pera artificial (zona caliente), esto se muestra a través de los dos semicírculos emblanquecidos dentro de la zona; en contraste, en la imagen 5 el participante fumador focalizó su mirada en la parte encendida del cigarro y en el cenicero, como lo indican los semicírculos de color más claro. En lo que respecta a las imágenes neutras, las miradas de los participantes fumadores y no fumadores se dispersan en toda la imagen como lo ilustran las imágenes 4 y 6 .

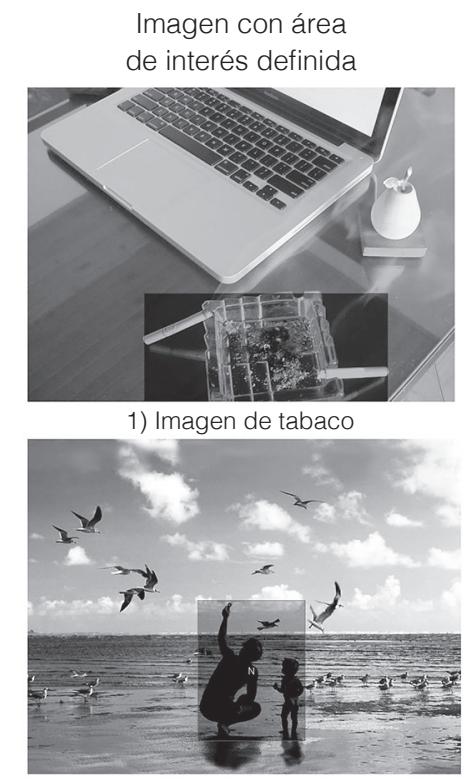

2) Imagen neutra
Mapa de calor en no fumadores

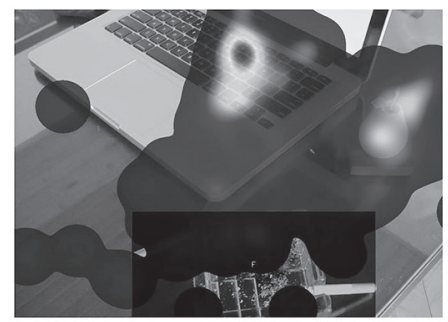

3) Imagen de tabaco

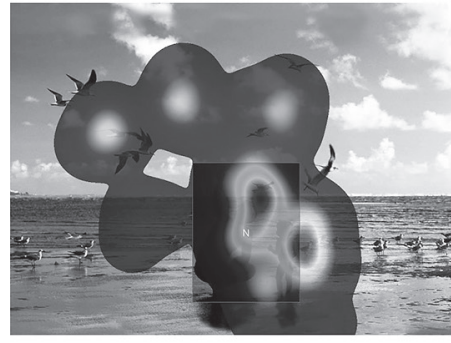

4) Imagen neutra
Mapa de calor de fumadores moderados

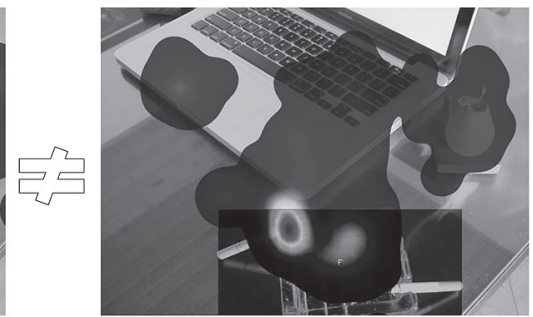

5) Imagen de tabaco
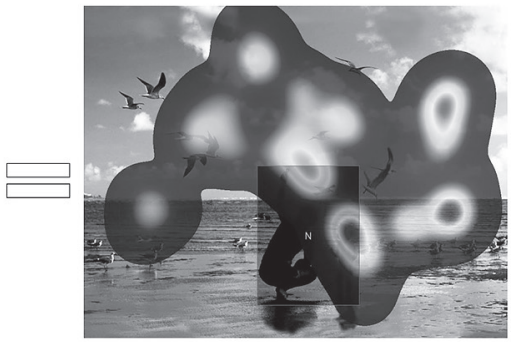

6) Imagen neutra nadas con el tabaco. De este modo, las tres mediciones conductuales y la distribución de la mirada registrada por medio de mapas de calor, en conjunto, dan cuenta de la consistencia de los resultados.

Por tanto, el registro de la atención a través de las variables antes mencionadas es coherente con una definición conductual de la atención, donde se considera qué organismo atiende a un aspecto particular del estímulo cuando un cambio del mismo produce variaciones sistemáticas en su conducta (Skinner, 1953). Durante la tarea experimental se presentaron dos tipos de imágenes, unas relacionadas con el consumo y otras definidas como neutras. Los participantes fumadores eligieron mirar más y por más tiempo las imágenes (estímulos) asociadas al consumo, mientras que en los no fumadores su mirada fue más dispersa, es decir prestaron menos atención a las mismas imágenes mostradas en las diapositivas. Los resultados observados en las tres medidas de atención y los mapas de calor sugieren que aquellos participantes que consumen tabaco son aparentemente más sensibles a estímulos asociados a su consumo, lo que es acorde a la teoría de sensibilización del incentivo (Robinson \& Berridge, 2008), ya que las señales relacio- nadas con el consumo de tabaco son más relevantes para las personas fumadoras, pues su atención estuvo focalizada a tales estímulos. El sesgo atencional queda evidenciado en el comportamiento y conducta observable de los participantes del GFM, aunque cabe señalar que tales modificaciones están enlazadas con la parte motivacional y neuronal (Hogarth \& Duka, 2006).

Algunas teorías del aprendizaje asociativo consideran que la atención depende de la relevancia de los estímulos predictivos y que esta cambia con la experiencia, de manera que al inicio del aprendizaje un organismo presta atención a todos los estímulos ambientales, pero con el paso del tiempo aprenderá a ignorar claves redundantes y a atender sólo estímulos relevantes (Mackintosh, 1975). Dicho planteamiento teórico podría dar cuenta de un sesgo atencional de los consumidores de tabaco (Hogarth et al., 2003; Vila, 2016), ya que en este estudio las imágenes relacionadas con el consumo de tabaco fueron relevantes y modularon la atención de los participantes. Evidencia de ello, son los resultados obtenidos en cada una de las mediciones conductuales de la atención y en los mapas de calor que muestran su distribución. 
En consecuencia, los resultados son coherentes con lo señalado por Robinson y Berridge (2008) sobre la función selectiva de la atención. Los participantes del GFM tuvieron mayor sensibilidad a los distintos estímulos asociados al consumo de tabaco (imágenes de ceniceros, encendedores, café, lugares, etc.) aumentando su atención a tales estímulos en comparación con los participantes del GNF. En síntesis, las tres medidas registradas en este estudio permiten identificar diferencias en la atención a estímulos relacionados con el uso de tabaco en personas fumadoras y no fumadoras que participaron en el estudio. Si bien el número de participantes fue limitado, el uso de más de una medida conductual de la atención visual da validez interna al trabajo, ya que es un aspecto no considerado anteriormente por otros autores (Field et al., 2011; Pérez, et al., 2019; Ventura et al., 2011). Asimismo, el análisis cualitativo agrega coherencia a los resultados debido a que son una representación visual del despliegue de la atención ante las imágenes presentadas.

En concordancia con lo anterior, los resultados del presente estudio tienen relación estrecha con el enfoque cognitivo-conductual, el cual tiene como base los principios de aprendizaje (Ruiz et al., 2017; Velázquez \& Córdova, 2017). Sin embargo, hasta el momento en los distintos niveles de intervención no se han considerado los factores atencionales y se omite su relación con los procesos de aprendizaje de las conductas adictivas, a pesar de que en los fumadores habituales los estímulos relacionados con el consumo les puede generar el deseo de fumar, ya que han desarrollado una sobrecarga de atención (Berridge \& Robinson, 2011) y los factores atencionales podrían contribuir a una mejor práctica aplicada y a su vez fomentar el desarrollo profesional en la investigación traslacional.

Los resultados preliminares encontrados permiten concluir que existe una diferencia en la atención visual entre los estudiantes universitarios fumadores y los no fumadores participantes del estudio. En concordancia con lo reportado por distintos autores (Crespo et al., 2007; Duchowski, 2017; Wu et al., 2018), la técnica de seguimiento ocular permite evaluar la atención en varias medidas conductuales que pueden ser consideradas como un índice de la atención; por lo que la latencia, el número de fijaciones y el porcentaje de tiempo en la zona de interés, en conjunto, permiten contar con medidas observables de la atención visual. Asimismo, los mapas de calor facilitan la observación del despliegue atencional y distribución de la atención de los participantes durante la presentación de las imágenes.

La mayor atención prestada a las imágenes relacionadas con el tabaco versus las imágenes neutras, sugiere que cuando un fumador atiende a un aspecto particular de un estímulo relevante pre-consumo, una variación del mismo produce cambios sistemáticos en su conducta que puede iniciar la acción de fumar.

Finalmente, se considera a la técnica de seguimiento ocular como una herramienta útil para el estudio de la atención en humanos desde un enfoque conductual. Posteriores investigaciones podrían incluir grupos más grandes de consumidores severos o con mayor dependencia al tabaco; incluso consumidores de otras sustancias, para observar un mejor contraste entre los grupos en las medidas cuantitativas y cualitativas observadas, a fin de confirmar y ampliar la consistencia de los presentes hallazgos.

\section{FUENTES DE FINANCIAMIENTO}

Esta investigación fue realizada con el apoyo del proyecto PAPIIT IN305920 de la Dirección General de Asuntos del Personal Académico (DGAPA) de la Universidad Nacional Autónoma de México.

\section{CONFLICTOS DE INTERÉS}

Los autores declaran no tener conflicto de interés.

\section{AGRADECIMIENTOS}

A Alma Nohemí Guzmán Blanco, Maximiliano Charbel Aguilar Espinosa, Arriaga Barajas César Enrique, por su ayuda en la recolección y captura de los datos.

\section{REFERENCIAS}

Berridge, K. C., \& Robinson, T. E. (2011). Drug addiction as incentive sensitization. Addiction and responsibility, 21-54.

Comisión Nacional contra las Adicciones. (2017). Encuesta Nacional de Consumo de Drogas, Alcohol y Tabaco (ENCODAT) 2016-2017. Recuperado de https://encuestas.insp.mx/ena/encodat2017/reporte_encodat_tabaco_2016_2017.pdf

Crespo, A., Cabestrero, R., Grzib, G., \& Quirós, P. (2007). Visual Attention to health warnings in tobacco advertisements: An eye-Tracking research between smokers and non-smokers. Studia Psychologica, 49(19)

De La Torre Benítez, G. (2002). El modelo funcional de atención en neuropsicología. Revista de psicología general y aplicada: Revista de la Federación Española de Asociaciones de Psicología, 55(1), 113-122.

Duchowski, A. T. (2017). Eye tracking methodology. Theory and practice, 328(614), 2-3.

Fagerström, K., Kunze, M., Schoberger, N., Breslau, Hughes, R., Hurt, Puska, P., Ramstrom, L. \& Zatonski, W. (1996). Nicotine dependence versus smoking prevalence: comparisons among countries and categories of smokers. Tob. Control, 5. 52-56. doi: 10.1136/tc.5.1.52 
Fernández, A. (2014). Neuropsicología de la atención. Conceptos, alteraciones y evaluación. Revista Argentina de Neuropsicología, 25(1), 1-28.

Field, M., Hogarth, L., Bleasdale, D., Wright, P., Fernie, G., \& Christiansen, P. (2011). Alcohol expectancy moderates attentional bias for alcohol cues in light drinkers. Addiction, 106(6), 10971103. doi:10.1111/j.1360-0443.2011.03412.x

Gantiva Diaz, C., Rodríguez Materón, M., Arias Ramírez, M., Rubio Guarín, E., Guerra Muñoz, P., \& Vila Castellar, J. (2012). Diseño y validación de un conjunto de imágenes afectivas relacionadas con el consumo de tabaco en población colombiana. Pensamiento Psicológico, 10(2). Recuperado de https://revistas.javerianacali.edu.co/index.php/pensamientopsicologico/article/view/405.

Hernández, H., Fernández C., \& Baptista, P. (2014). Metodología de la Investigación Científica. 6ta edición. McGraw-Hill.

Hogarth, L., Dickinson, A., Janowski, M., Nikitina, A., \& Duka, T. (2008). The role of attentional bias in mediating human drug-seeking behaviour. Psychopharmacology, 201(1), 29-41. doi:10.1007/ s00213-008-1244-2

Hogarth, L.\& Duka, T. (2006). Human nicotine conditioning requires explicit contingency knowledge: Is addictive behaviour cognitively mediated? Psychopharmacology. 184. 553-66. doi: 10.1007/s00213-005-0150-0.

Hogarth, L. C., Mogg, K., Bradley, B. P., Duka, T., \& Dickinson, A. (2003). Attentional orienting towards smoking-related stimuli. Behavioural pharmacology, 14(2), 153-160. doi: 10.1097/00008877200303000-00007

Instituto de Efectividad Clínica y Sanitaria. (2017). El tabaquismo en México. Junio 2017, Buenos Aires, Argentina. Recuperado de ttp://www. iecs.org.ar/wpcontent/uploads/Flyer_tabaquismo_MEXICO.pdf.

Levy, L. C. N., Humarán, I. M., Arcos, M. A. Á., Andrade, M. A. R., Lazcano-Ponce, E., \& Hernández-Ávila, M. (2017). Encuesta Global de Tabaquismo en Adultos (GATS). México 2015. Recuperado de https://xipe.insp.mx/resources/images/stories/2017/ Avisos/docs/180315_gats_espanol_2015.pdf

Lang, P. J., Bradley, M. M., \& Cuthbert, B. N. (2005). International affective picture system (IAPS): Digitized photographs, instruction manual and affective ratings. (Technical Report A-6). University of Florida.

Mackintosh, N. J. (1975). A theory of attention: Variations in the associability of stimuli with reinforcement. Psychological Review, 82(4), 276-298. doi : 10.1037/h0076778

Morales, Z., Pascual, L., \& Garrido, R. (2013). Valoración de sesgos atencionales visuales en una muestra de fumadores universitarios. Adicciones, 25(2), 163-169. https://www.redalyc.org/articulo.oa?id=289126458009

Munar, E., Rosselló, J., \& Sánchez, A. (1999). Atención y percepción. Alianza.
Oficina de las Naciones Unidas contra la Droga y el Delito. (2019). Informe mundial sobre las drogas 2019. Recuperado de https:// wdr.unodc.org/wdr2019/prelaunch/WDR2019_B1_S.pdf.

Orain-Pelissolo, S., Grillon, C., Perez-Diaz, F. \& Jouvent, R. (2004). Lack of startle modulation by smoking cues in smokers. Psychopharmacology 173, 160-166. doi: 10.1007/s00213-003-1715-4

Organización Mundial de la Salud. (2019). Tabaco. Recuperado de https://www.who.int/es/news-room/fact-sheets/detail/tobacco

Pérez-Tehoyotl, J., Rojas Iturria, F., \& Vila Carranza, J. (2019). El seguimiento ocular como una medida conductual de la atención empleando diapositivas del IAPS. Revista de Psicología y Ciencias del Comportamiento de la Unidad Académica de Ciencias Jurídicas y Sociales, 10(1), 63-73. doi: 10.29059/rpcc.20190602-81.

Petersen, SE. \& Posner, MI. (2012). El sistema de atención del cerebro humano: 20 años después. Revisión anual de neurociencia, 35, 73-89. doi: 10.1146/annurev-neuro-062111-150525.

Robinson, T., \& Berridge K. (2008). The incentive sensitization theory of addiction: some current issues. 363Phil. Trans. R. Soc. B doi: 10.1098/rstb.2008.0093

Ruiz, M., Díaz, M., \& Villalobos, A. (2017). Manual de técnicas y terapias cognitivo-conductuales. Desclée de Brouwer.

Shankleman, M., Sykes, C., Mandeville, K., Di Costa, S., \& Yarrow, K. (2015). Standardised (plain) cigarette packaging increases attention to both text-based and graphical health warnings: experimental evidence. Public Health, 129, 37-42, doi: 10.1016/j. puhe.2014.10.019

Skinner, B.F. (1953). Science and human behavior. Macmillan.

Sociedad Mexicana de Psicología. (2009). Código ético del psicólogo. Trillas.

Velázquez, M., \& Córdova, A. (2017). Sistema institucional de evaluación de programas de tratamiento: evaluación de la clínica para dejar de fumar CIJ. Centros de Integración Juvenil. Recuperado de http://www.cij.gob.mx/programas/Investigacion/pdf/11-14.pdf

Ventura, C., Poy, R., Segarra, P., López, R., Esteller, À., Fonfría, A., Ribes, P., \& Moltó, J. (2011). Sesgos atencionales en adictos a la cocaína. Fòrum de Recerca, (16), 931-940.

Vila, J. (2016). Adicción y Aprendizaje. Revista Iberoamericana de Psicología, 8(2), 79 - 89. doi: 10.33881/2027-1786.rip.8207

Vila, J., Bernal, R., \& Monroy, A. (2017). Atención y ensombrecimiento Pavloviano. En Nieto, J., \& Bernal (Ed.), Estudios contemporáneos en cognición comparada, pp. 15-39. México, Universidad Nacional Autónoma de México.

Wu, D., Gao, Y., \& Miao, D. (2018). Using an eye tracker to measure information processing according to need for cognition level. Social Behavior and Personality: An International Journal, 46(11), 1869+. Retrieved from https://link.gale.com/apps/doc/A562974321/PPPC?u=unilamex\&sid=PPPC\&xid $=5473128$ 